\title{
Neutrophil extracellular traps in patients with pulmonary tuberculosis
}

\author{
Anne Jan van der Meer ${ }^{1 *}$, Sacha Zeerleder ${ }^{2,5}$, Dana C. Blok, Liesbeth M. Kager ${ }^{1}$, Ivar O. Lede ${ }^{3}$, Wahid Rahman ${ }^{6}$, \\ Rumana Afroz ${ }^{6}$, Aniruddha Ghose ${ }^{6}$, Caroline E. Visser ${ }^{3}$, Abu Shahed Md Zahed ${ }^{6}$, Md Anwar Husain $^{7}$, \\ Khan Mashrequl Alam ${ }^{7}$, Pravat Chandra Barua ${ }^{8}$, Mahtabuddin Hassan ${ }^{6}$, Md Abu Tayab ${ }^{9}$, Arjen M. Dondorp ${ }^{10}$ \\ and Tom van der Poll ${ }^{1,4}$
}

\begin{abstract}
Tuberculosis is a devastating infectious disease causing many deaths worldwide. Recent investigations have implicated neutrophil extracellular traps (NETs) in the host response to tuberculosis. The aim of the current study was to obtain evidence for NETs release in the circulation during human tuberculosis. For this we measured the plasma concentrations of nucleosomes in conjunction with neutrophil elastase, in 64 patients with active pulmonary tuberculosis and 32 healthy controls. Patients with active tuberculosis had elevated plasma levels of nucleosomes and elastase when compared with local healthy blood donors. Furthermore nucleosome and elastase levels showed a positive correlation. These findings provide the first evidence for the release of NETs in the circulation of patients with active pulmonary tuberculosis.
\end{abstract}

\section{To the editor,}

The global burden of tuberculosis is high, with 10.4 million cases and 1.4 million deaths in 2015. Especially in Bangladesh the disease is highly prevalent, with 225 new cases per 100,000 citizens in 2015 (Global Tuberculosis Report World Health Organization 2016). While CD4+ T cells and type 1 cytokines are well-studied components of protective immunity after infection with the causative agent Mycobacterium (M.) tuberculosis, recent investigations also point to a role for neutrophils in the host response during tuberculosis [1]. Neutrophils are the cell types predominantly infected with $M$. tuberculosis in patients with active pulmonary tuberculosis [2] and the blood transcriptional signature associated with human tuberculosis is driven by neutrophil-specific gene expression profiles [3]. While neutrophils are not able to kill M. tuberculosis [4], they may assist in host defense and containment of the infection by interacting with other cell types [1]. Neutrophils can release neutrophil extracellular traps (NETs) composed of nucleosomes,

\footnotetext{
* Correspondence: ajvdrmeer@gmail.com

${ }^{1}$ Centre for Experimental and Molecular Medicine, Academic Medical Center, University of Amsterdam, Meibergdreef 9, Room G2-130, 1105, AZ,

Amsterdam, The Netherlands

Full list of author information is available at the end of the article
}

histones and granular proteases such as elastase [5]. NETs can exert antimicrobial effects, in part mediated through their ability to trap pathogens [5]. Recent investigations have implicated NETs in the host response to tuberculosis. Neutrophils release NETs upon incubation with $M$. tuberculosis in vitro [6-8] and sputum of patients with tuberculosis contains NETs [8]. The aim of the current study was to obtain evidence for NETs release in the circulation during human tuberculosis. For this we measured the plasma concentrations of nucleosomes, a suitable marker for NETs formation in plasma in humans $[9,10]$, in conjunction with neutrophil elastase, in patients with active pulmonary tuberculosis.

Sixty one patients (age 28 [22-44] years) and 32 healthy blood donors (30 [24-35] years) were recruited in the Tuberculosis Clinic of Chittagong General Hospital and the Chittagong Medical College \& Hospital, Chittagong, Bangladesh (Table 1). The study was approved by the National Research Ethics Committee, Bangladesh Medical Research Council, Bangladesh and the Oxford Tropical Research Ethics Committee, University of Oxford, Oxford, UK (OXTREC 35-09). Written informed consent was obtained from all study subjects or next-of-kin by a native Bengali speaker. These subjects were part of a larger population in which 
Table 1 Patient characteristics

\begin{tabular}{|c|c|c|}
\hline & $\begin{array}{l}\text { Healthy controls } \\
n=32\end{array}$ & $\begin{array}{l}\text { Primary TB } \\
n=61\end{array}$ \\
\hline \multicolumn{3}{|l|}{ Demographics } \\
\hline Age (years) & $30(24-35)$ & $28(22-43,5)$ \\
\hline Male sex $(n)$ & $25(78 \%)$ & $44(72 \%)$ \\
\hline Smoker $(n)$ & $8(25 \%)$ & $30(49 \%)$ \\
\hline $\begin{array}{l}\text { Affected family member } \\
\text { with TB }(n)\end{array}$ & $0(0 \%)$ & $6(10 \%)$ \\
\hline BCG-vaccinated $(n)$ & $20(63 \%)$ & $21(34 \%)$ \\
\hline HIV-positive (ii) & $0(0 \%)$ & $2(3 \%)$ \\
\hline \multicolumn{3}{|l|}{ Symptoms } \\
\hline Fever $(n)$ & $0(0 \%)$ & $61(100 \%)$ \\
\hline Night sweats $(n)$ & $0(0 \%)$ & $23(38 \%)$ \\
\hline Weight loss (n) & $0(0 \%)$ & $44(72 \%)$ \\
\hline Fatigue $(n)$ & $1(3 \%)$ & $32(52 \%)$ \\
\hline Shortness of breath (n) & $1(3 \%)$ & $7(11 \%)$ \\
\hline Productive cough $(n)$ & $3(9 \%)$ & $56(92 \%)$ \\
\hline \multicolumn{3}{|l|}{ Signs } \\
\hline Temperature $\left({ }^{\circ} \mathrm{C}\right)$ & $36.9(36.5-37.1)$ & $37.2(36.9-38.1)^{* * *}$ \\
\hline MAP (mmHg) & 83 (79-93) & $80(70-87)^{*}$ \\
\hline Heart rate (bpm) & $80(78-84)$ & $90(80-100)^{* * *}$ \\
\hline Respiratory rate (brpm) & $20(20-24)$ & $24(22-28)^{* * *}$ \\
\hline $\mathrm{BMI}\left(\mathrm{W} / 1^{2}\right)$ & $24.3(22.7-26.0)$ & $17.6(15.6-19.6)^{* * *}$ \\
\hline
\end{tabular}

Abbreviations: $B M I$ body mass index, expressed as weight $(w)$ divided by length (I)2; bpm beats per minute, brpm breaths per minute, MAP mean arterial blood pressure, $n$ total number, TB tuberculosis. Percentages given are within study group. Data are medians with interquartile ranges. ${ }^{*} P<0.05$, ${ }^{* *} P$ $<0.001$ for the difference between primary TB or recurrent TB-patients versus controls

the expression of Toll-like receptor regulators was studied [11]. Inclusion and exclusion criteria have been reported in detail [11]. The study subjects were all newly registered patients who had not (yet) received therapy at the time of enrolment. On-site tuberculosis confirmation was defined by a minimum of two out of three positive Ziehl-Neelsen stained sputum samples collected on two consecutive days. $M$. tuberculosis infection was confirmed by polymerase chain reaction (GeneXpert, Cepheid, Solna, Sweden). White blood cells were manually counted by blood smear. All patients and controls were tested for human immunodeficiency virus (Determine ${ }^{\circ}$ HIV 1/2 test; Almere, Tilburg, The Netherlands). Nucleosomes, elastase- $\alpha 1$-antitrypsin and factor VII-activating protease (FSAP)- $\alpha 2$-antiplasmin complexes were measured in citrate-anticoagulated plasma by enzymelinked immunosorbent assays as described $[10,12]$. The nucleosome ELISA uses a catching antibody that recognizes histone 3 and a detection antibody that recognizes an epitope exposed on complexes of histone $2 \mathrm{~A}$, histone $2 \mathrm{~B}$ and double stranded DNA [10]. Comparisons between groups were performed by Mann-Whitney $U$ tests and correlations were calculated by Spearman's rho test using GraphPad Prism version 5.01 (GraphPad Software, San Diego, CA). Data are presented as medians with interquartile ranges. $P<0.05$ was considered statistically significant.

Demographic data, together with clinical signs and symptoms, are shown in the Table 1. Patients did not have significant comorbidities. Relative to healthy controls, tuberculosis patients had leucocytosis (Fig. 1, panel A) caused by a rise in neutrophil counts (Fig. 1, panel B). Patients with active tuberculosis showed elevated plasma levels of nucleosomes when compared with local healthy blood donors $(111.7 \mathrm{U} / \mathrm{ml}$ versus $5.4 \mathrm{U} / \mathrm{ml}, P<0.0001$; Fig. 1, panel C). Plasma elastase concentrations were also higher in patients with tuberculosis $(854.0 \mathrm{ng} / \mathrm{ml}$ versus $397.3 \mathrm{ng} / \mathrm{ml}$ in healthy donors, $\mathrm{P}<0.0001$; Fig. 1 , panel D), and nucleosome and elastase levels showed a positive correlation (Spearman's rho $0.37, P<0.005$; Fig. 1, panel E). Tuberculosis patients more often smoked than healthy controls (49\% versus $25 \%$ respectively, Table 1) and a recent study showed nicotine has NETs inducing properties [13]. However, comparing nucleosomes and elastase levels between smokers and non-smokers within the tuberculosis patient group showed no significant differences (data not shown).

Elastase is an important component of NETs that can assist in the degradation of bacterial virulence factors [5]. Upon activation of neutrophils elastase translocates to the nucleus, where it aids in chromatin decondensation leading to NETosis [5]. Additionally, elastase can activate macrophages and increase their capacity to kill intracellular pathogens [14]. Moreover, macrophages can bind $M$. tuberculosis induced NETs and ingest elastase from neutrophils, leading to the release of increased amounts of proinflammatory cytokines [7] like we found in the tuberculosis patients included in this study [11]. Together these data suggest that during tuberculosis elastase could be involved in an interaction between NETotic cells and macrophages resulting in a proinflammatory and protective immune response. Notably, this interaction between NETs, elastase and other host cells may also be associated with collateral damage, as has been described in a variety of infectious and inflammatory diseases [5].

Two patients (3\%) and none of the blood donors tested positive for HIV (Table 1). The low prevalence of HIV positive tuberculosis in our cohort is in accordance with data from the World Health Organization derived from Bangladesh (Global Tuberculosis Report World Health Organization 2016 and allowed us to study the association between tuberculosis and NETs formation without the potential bias introduced by concurrent HIV infection. Indeed, HIV, like M. tuberculosis (6-8), triggers NETs release from neutrophils [15]. 




FSAP circulates as a single-chain molecule and is activated upon contact with apoptotic and necrotic cells [16]. Activated FSAP mediates the release of nucleosomes from apoptotic cells [16]. Acute infections, particularly sepsis, are associated with an increased activity of FSAP [12]. In our cohort plasma FSAP activation as measured by FSAP- $\alpha 2$-antiplasmin complexes did not differ between tuberculosis patients and controls (Fig. 1, panel F), suggesting that FSAP may not contribute to nucleosome release in this population. The absence of increased FSAP activity further suggests that nucleosome release during tuberculosis is caused by NETosis rather than by apoptosis or necrosis [17]. In this context it is interesting to note that neutrophil apoptosis is not required for $M$. tuberculosis induced NETosis [7].

Our study has limitations. Duration of symptoms was not documented. Our data do not prove that plasma nucleosomes are solely or predominantly derived from neutrophils. The poor resource setting and the relatively small sample size precluded careful evaluation between disease severity and nucleosome levels. In addition, the lack of follow up samples excluded analyses of sequential nucleosome levels and disease course. None of the patients died from tuberculosis.

In conclusion, we here provide evidence for the release of NETs in the circulation of patients with active pulmonary tuberculosis, corroborating previous studies showing the capacity of $M$. tuberculosis to induce NETs release from neutrophils in vitro [6-8]. Our study does not reveal whether plasma nucleosomes originate from infected lesions or from systemic release, although the concurrently elevated plasma elastase levels and the fact that tuberculosis is associated with altered gene expression in blood neutrophils [3] suggest that the latter option is more likely. The exact role of NETs in the host response during tuberculosis, whether contributing to protective immunity or causing collateral damage, requires further investigation.

\section{Acknowledgements}

Not applicable.

\section{Funding}

This work was supported by ZonMW [grant number 92003504, to L.M.K.], Stichting BeGeTu and the Mr. Willem Bakhuys Roozeboom Stichting. The funding was used for laboratory expenses and personnel costs.

\section{Availability of data and materials}

The datasets generated during and/or analysed during the current study are available from the corresponding author on reasonable request.

\section{Authors' contributions}

AJM and SZ participated in the design of the study, analysis and interpretation of data and the writing of the manuscript. DCB and LMK participated in the design of the study, collection and processing of samples. IOL was part of the collection and processing of samples and the interpretation of microbiological assays. WR, RA and AG were the native speakers who helped with patient inclusion and sample collection. CEV participated in the design and microbiological interpretation of results. ASMZ, MAH, KMA, PCB, MH and MAT took part 
in the design and implementation of the study in Bangladesh. AMD took part in study design and implementation. TvdP was responsible for study design, data interpretation and manuscript writing. All authors read, commented on and approved the final manuscript. All authors read and approved the final manuscript.

\section{Ethics approval and consent to participate}

The study was approved by the National Research Ethics Committee, Bangladesh Medical Research Council, Bangladesh and the Oxford Tropical Research Ethics Committee, University of Oxford, Oxford, UK (OXTREC 35-09). Written informed consent was obtained from all study subjects or next-of-kin by a native Bengali speaker.

\section{Consent for publication}

Not applicable.

\section{Competing interests}

The authors declare that they have no competing interests.

\section{Publisher's Note}

Springer Nature remains neutral with regard to jurisdictional claims in published maps and institutional affiliations.

\section{Author details}

${ }^{1}$ Centre for Experimental and Molecular Medicine, Academic Medical Center, University of Amsterdam, Meibergdreef 9, Room G2-130, 1105, AZ, Amsterdam, The Netherlands. ${ }^{2}$ Department of Haematology, Academic Medical Center, University of Amsterdam, Amsterdam, The Netherlands. ${ }^{3}$ Department of Microbiology, Academic Medical Center, University of Amsterdam, Amsterdam, The Netherlands. ${ }^{4}$ Division of Infectious Diseases, Sanquin Blood Supply and Landsteiner Laboratory of the Academic Medical Center, University of Amsterdam, Amsterdam, The Netherlands. ${ }^{5}$ Department of Immunopathology, Chittagong Medical College \& Hospital (CMCH), Chittagong, Bangladesh. ${ }^{6}$ Department of Internal Medicine, Chittagong Medical College \& Hospital (CMCH), Chittagong, Bangladesh. ${ }^{7}$ Department of Microbiology, Chittagong Medical College \& Hospital (CMCH), Chittagong, Bangladesh. ${ }^{8}$ National TB Control \& Leprosy Elimination Program, Dhaka, Bangladesh. ${ }^{9}$ Chittagong General Hospital, Chittagong, Bangladesh. ${ }^{10}$ Mahidol Oxford Tropical Medicine Research Unit, Mahidol University, Bangkok, Thailand.

Received: 2 March 2017 Accepted: 12 October 2017

Published online: 30 October 2017

\section{References}

1. Lerner TR, Borel S, Gutierrez MG. The innate immune response in human tuberculosis. Cell Microbiol. 2015;17(9):1277-85.

2. Eum SY, Kong JH, Hong MS, Lee YJ, Kim JH, Hwang SH, et al. Neutrophils are the predominant infected phagocytic cells in the airways of patients with active pulmonary TB. Chest. 2010;137(1):122-8.

3. Berry MP, Graham CM, McNab FW, Xu Z, Bloch SA, Oni T, et al. An interferon-inducible neutrophil-driven blood transcriptional signature in human tuberculosis. Nature. 2010;466(7309):973-7.

4. Corleis B, Korbel D, Wilson R, Bylund J, Chee R, Schaible UE. Escape of mycobacterium tuberculosis from oxidative killing by neutrophils. Cell Microbiol. 2012;14(7):1109-21.

5. Yipp BG, Kubes P. NETosis: how vital is it? Blood. 2013;122(16):2784-94.

6. Ramos-Kichik V, Mondragon-Flores R, Mondragon-Castelan M, GonzalezPozos S, Muniz-Hernandez S, Rojas-Espinosa O, et al. Neutrophil extracellular traps are induced by mycobacterium tuberculosis. Tuberculosis (Edinb). 2009;89(1):29-37.

7. Braian C, Hogea V, Stendahl O. Mycobacterium tuberculosis- induced neutrophil extracellular traps activate human macrophages. J Innate Immun. 2013;5(6):591-602.

8. Ong CW, Elkington PT, Brilha S, Ugarte-Gil C, Tome-Esteban MT, Tezera LB, et al. Neutrophil-derived MMP-8 drives AMPK-dependent matrix destruction in human pulmonary tuberculosis. PLoS Pathog. 2015;11(5):e1004917.

9. Fuchs TA, Kremer Hovinga JA, Schatzberg D, Wagner DD, Lammle B. Circulating DNA and Myeloperoxidase indicate disease activity in patients with thrombotic microangiopathies. Blood 2012;120(6):1157-1164.
10. van Montfoort ML, Stephan F, Lauw MN, Hutten BA, Van Mierlo GJ, Solati S, et al. Circulating nucleosomes and neutrophil activation as risk factors for deep vein thrombosis. Arterioscler Thromb Vasc Biol. 2013;33(1):147-51.

11. Blok DC, Kager LM, Hoogendijk AJ, Lede IO, Rahman W, Afroz R, et al. Expression of inhibitory regulators of innate immunity in patients with active tuberculosis. BMC Infect Dis. 2015;15:98.

12. Stephan F, Hazelzet JA, Bulder I, Boermeester MA, van Till JO, van der Poll T, et al. Activation of factor VII-activating protease in human inflammation: a sensor for cell death. Crit Care. 2011;15(2):R110.

13. Lee J, Luria A, Rhodes C, Raghu H, Lingampalli N, Sharpe O, et al. Nicotine drives neutrophil extracellular traps formation and accelerates collageninduced arthritis. Rheumatology (Oxford). 2017;56(4):644-53.

14. Ribeiro-Gomes FL, Moniz-de-Souza MC, Alexandre-Moreira MS, Dias WB, Lopes MF, Nunes MP, et al. Neutrophils activate macrophages for intracellular killing of Leishmania major through recruitment of TLR4 by neutrophil elastase. J Immunol. 2007;179(6):3988-94.

15. Saitoh T, Komano J, Saitoh Y, Misawa T, Takahama M, Kozaki T, et al. Neutrophil extracellular traps mediate a host defense response to human immunodeficiency virus-1. Cell Host Microbe. 2012;12(1):109-16.

16. Stephan F, Aarden LA, Zeerleder S. FSAP, A new player in inflammation? Hamostaseologie. 2012;32(1):51-5.

17. Fuchs TA, Abed U, Goosmann C, Hurwitz R, Schulze I, Wahn V, et al. Nove cell death program leads to neutrophil extracellular traps. J Cell Biol. 2007;176(2):231-41.

\section{Submit your next manuscript to BioMed Central and we will help you at every step:}

- We accept pre-submission inquiries

- Our selector tool helps you to find the most relevant journal

- We provide round the clock customer support

- Convenient online submission

- Thorough peer review

- Inclusion in PubMed and all major indexing services

- Maximum visibility for your research

Submit your manuscript at www.biomedcentral.com/submit
) Biomed Central 